\title{
Biologic Treatments of Psoriasis: An Update for the Clinician
}

This article was published in the following Dove Press journal:

Biologics: Targets and Therapy

\section{Nicholas D Brownstone Julie Hong Megan Mosca \\ Edward Hadeler \\ Wilson Liao (D) \\ Tina Bhutani \\ John Koo}

University of California, San Francisco, Department of Dermatology, Psoriasis and Skin Treatment Center, San Francisco, CA, USA

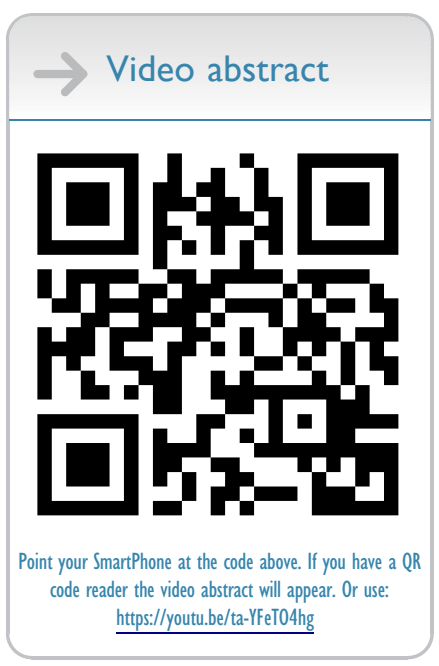

Correspondence: Nicholas

D Brownstone

University of California, San Francisco, Department of Dermatology, Psoriasis and Skin Treatment Center, 5 I 5 Spruce Street, San Francisco, CA, 94II8, USA

$\mathrm{Tel}+\mid$ 4I5-476-4019

$\mathrm{Fax}+1$ 415-502-4126

Email Nicholas.Brownstone@ucsf.edu

\begin{abstract}
The advent of biologic agents within the past two decades has dramatically improved the treatment of psoriasis and psoriatic arthritis. Given that there now exists 11 FDA approved biologic options available for psoriasis, with more in the pipeline, the therapeutic armamentarium has been greatly enhanced. However, the fact that there are so many available options has also caused confusion for providers. Therefore, this manuscript deliberately focuses on the most clinically useful facts (such as efficacy and safety data) about each and every FDA approved biologic agent (including pipeline agents) for psoriasis. Moreover, among the clinically relevant facts, this manuscript purposely emphasizes the unique merits and demerits of each agent to make it easier for the provider to select which one of these many options is the best for the particular patient on hand. The goal of this manuscript is to aid the busy practicing dermatologist in becoming more adept at using these agents with the ultimate aim of improving patient care.
\end{abstract}

Keywords: biologic therapy, psoriasis, IL-17, TNF-alpha, IL 12/23, psoriatic arthritis, IL-23

\section{Introduction}

The advent of biologic agents within the past two decades has dramatically improved the treatment of psoriasis and psoriatic arthritis. Before biologic agents became available, only oral options such as methotrexate, were available to treat moderate-to-severe cases of psoriasis systemically. Even though methotrexate was fairly effective in treating psoriasis, the safety profile is far from ideal. For example, methotrexate has over ten black box warnings with some of them involving risk of death. Other traditional oral options such as oral retinoids and cyclosporine also have other serious black box warnings. With biologic agents, there now exists options that are much more effective than medications like methotrexate but without any black box warnings whatsoever. Another advantage is that some of the more recent biologic agents require only four injections per year during the maintenance phase of treatment.

It is clear that great progress has been made with biologic therapy for psoriasis in terms of both the safety and efficacy of these agents. This new treatment paradigm was made possible by the continually advancing knowledge of the pathophysiology of psoriasis. Thirty years ago, psoriasis was still primarily considered a problem with the hyperproliferation of the epidermis. Recent research into the pathophysiology of psoriasis has highlighted the importance of the immune system in this disease. There now exists a clear mechanism, down to the molecular level, regarding which cytokines are implicated in the pathophysiology of psoriatic 
disease. In the initial cascade of psoriasis pathophysiology, a variety of cell types are involved which include keratinocytes, natural killer T cells, plasmacytoid dendritic cells and macrophages. These cells secrete cytokines which activate myeloid dendritic cells and in turn, activated myeloid dendritic cells secrete IL-12 and IL-23. Both of these cytokines are integral in the cellular cascade of psoriasis pathophysiology. IL-12 causes differentiation of native $\mathrm{T}$ cells to Th1 cells (which produce IFN- $\gamma$ and TNF- $\alpha$ ) and IL-23 is important for the proliferation of Th17 and Th22 cells. Th17 cells produce IL-17, IL-22 and TNF- $\alpha^{1}$ When considering all of these different molecular signaling pathways, IL-23 mediated activated of the Th17 pathway is hypothesized to be the main contributor to the inflammation seen in psoriasis. ${ }^{2}$ Given that the IL17 and IL-23 biologic agents are more effective may demonstrate the fact that these pathways are more important in the pathophysiology of psoriasis and that psoriasis patients may, on the whole, exhibit more pathology in this specific pathway.

The fact that biologic agents interact with a specific cytokine (such as TNF- $\alpha$, IL-17 or IL-23) in a targeted manner has revolutionized the capacity to treat psoriasis compared to the era of a more generalized immunosuppression reflected by the traditional oral medications. This represents an improved treatment regimen where targeted immunomodulation has resulted in a great enhancement in both safety and efficacy for biologic agents.

Given that there now exists 11 FDA approved biologic options available for psoriasis, with more in the pipeline, the therapeutic armamentarium has been greatly enhanced. However, the fact that there are so many available options has also caused confusion for providers. As a result, many providers may select a biologic agent at random. Therefore, this manuscript deliberately focuses on the most clinically useful facts about each and every FDA approved biologic agent (including pipeline agents) for psoriasis. Moreover, among the clinically relevant facts, this manuscript purposely emphasizes the unique merits and demerits of each agent to make it easier for the provider to select which one of these many options is the best for the particular patient on hand. As is true in medicine in general, the treatment of psoriasis with biologic agents is both an art and a science. The goal of this manuscript is to aid the busy practicing dermatologist in becoming more adept at using these agents with the ultimate aim of improving patient care. Each biologic agent will be presented according to the class that it belongs to. These agents will also be summarized in Table 1.

\section{TNF-Alpha Agents Etanercept $\left(\right.$ Enbrel $\left.^{\circledR}\right)$}

Etanercept is a recombinant human TNF- $\alpha$ receptor protein fused with the Fc portion of IgG1 that binds to soluble and membrane bound TNF- $\alpha$ and to tumor necrosis factor- $\beta .^{3}$ It is currently approved for treatment of moderate-to-severe adult and pediatric plaque psoriasis, psoriatic arthritis, rheumatoid arthritis, juvenile rheumatoid arthritis and ankylosing spondylitis. The approved dosing for etanercept in psoriasis is $50 \mathrm{mg}$ given SC twice weekly for the first 12 weeks followed by $50 \mathrm{mg}$ once weekly thereafter. The use of etanercept has greatly diminished over the last 10 years ago when it was clearly the market leader after efalizumab (Raptiva ${ }^{\circledR}$ ) was withdrawn from the market due to its association with progressive multifocal leukoencephalopathy caused by JC virus. ${ }^{4}$ During the first three months of therapy when etanercept is allowed to be used twice a week, $49 \%$ of the patients achieved PASI 75 by week 12 . However, this twice a week dosing was allowed for only the first 3 months: the rest of the time, etanercept injection is limited to only once a week. If etanercept is used for psoriasis patients once a week from the start, only $34 \%$ of the patients achieved PASI 75 by week $12 .^{5}$ At week $24,44 \%$ of those receiving $25 \mathrm{mg}$ twice weekly and $59 \%$ of those receiving $50 \mathrm{mg}$ twice weekly achieved PASI $75 .^{6}$ This efficacy was well appreciated when etanercept was the only agent available but now with the advent of other antiTNF agents, especially adalimumab, followed by even more efficacious anti-IL-17 and anti-IL-23 agents, etanercept efficacy is clearly seen as inferior. However, even today, etanercept has usefulness for special sub-populations. For example, etanercept has one of the best safety statements for use in geriatric patients with severe psoriasis. In the geriatric statement section of the FDA package insert, it reports that elderly patients have no increased occurrence of adverse events as compared to younger patients. Moreover, because of etanercept's outstanding safety track record, now for more than 20 years, it became the first biologic agent for psoriasis to be approved for pediatric use down to 4 years old. Etanercept has less of a tuberculosis risk compared to other TNF- $\alpha$ agents (adalimumab and infliximab).

\section{Adalimumab (Humira ${ }^{\circledR}$ )}

Adalimumab is a recombinant, fully human, monoclonal antibody against TNF-alpha that blocks the interaction of 
Table I Biologic Treatments of Psoriasis

\begin{tabular}{|c|c|c|c|c|c|}
\hline $\begin{array}{l}\text { Medication, } \\
\text { Year of FDA } \\
\text { Approval }\end{array}$ & $\begin{array}{l}\text { Brand } \\
\text { Name }\end{array}$ & FDA Approved for & Dosing Regimen & $\begin{array}{l}\text { Alternative Dosing } \\
\text { Regimen }\end{array}$ & Key Merit \\
\hline \multicolumn{6}{|c|}{ TNF-alpha inhibitors } \\
\hline $\begin{array}{l}\text { Adalimumab, } \\
2002\end{array}$ & Humira $^{\circledR}$ & $\begin{array}{l}\text { RA, PsO, PsA, AS, CD, } \\
\text { Pediatric CD, UC, HS } \\
\text { (age }>12 \text { ), uveitis, } \\
\text { polyarticular JIA }\end{array}$ & $\begin{array}{l}80 \mathrm{mg} \text { SC at week } 0, \\
40 \mathrm{mg} \text { at week } \mathrm{I}, \\
\text { then } 40 \mathrm{mg} \text { SC } \mathrm{q} 2 \mathrm{w}\end{array}$ & & $\begin{array}{l}\text { One of the most efficacious for } \\
\text { psoriatic arthritis with FDA } \\
\text { approval for inhibition of joint } \\
\text { destruction }\end{array}$ \\
\hline $\begin{array}{l}\text { Etanercept, } \\
2004\end{array}$ & Enbrel $^{\circledR}$ & $\begin{array}{l}\text { RA, PsO, PsA, AS, JIA, } \\
\text { pediatric PsO }\end{array}$ & $\begin{array}{l}50 \mathrm{mg} \text { SC twice } \\
\text { weekly for first } 12 \\
\text { weeks, then } 50 \mathrm{mg} \text { SC } \\
\text { weekly }\end{array}$ & & $\begin{array}{l}\text { Safe for use in geriatric patients } \\
\text { with severe psoriasis }\end{array}$ \\
\hline $\begin{array}{l}\text { Infliximab, } \\
2006\end{array}$ & Remicade $^{\circledR}$ & $\begin{array}{l}\text { RA, CD, PsO, PsA, AS, } \\
\text { UC, Pediatric CD, } \\
\text { Pediatric UC }\end{array}$ & $\begin{array}{l}5 \mathrm{mg} / \mathrm{kg} \mathrm{IV} \text { at weeks } \\
0,2 \text { and } 6 \text { and } \\
\text { thereafter every } 8 \\
\text { weeks }\end{array}$ & & $N / A$ \\
\hline $\begin{array}{l}\text { Certolizumab } \\
\text { pegol, } 2008\end{array}$ & Cimzia ${ }^{\circledR}$ & $\begin{array}{l}\mathrm{RA}, \mathrm{CD}, \mathrm{PsO}, \mathrm{Ps} A, \mathrm{AS} \\
\mathrm{nr} \text {-axSpA }\end{array}$ & $\begin{array}{l}\text { Patient weight >90kg: } \\
400 \mathrm{mg} \mathrm{SC} \mathrm{q} 2 \mathrm{w}\end{array}$ & $\begin{array}{l}\text { Patient weight }<90 \mathrm{~kg} \text { : } \\
400 \mathrm{mg} \mathrm{SC} \text { at weeks } 0 \text {, } \\
2 \text { and } 4 \text {, then } 200 \mathrm{mg} \\
\text { SC q2w }\end{array}$ & $\begin{array}{l}\text { Safe for use in pregnant and nursing } \\
\text { patients }\end{array}$ \\
\hline \multicolumn{6}{|c|}{ IL-I 7 inhibitors } \\
\hline $\begin{array}{l}\text { Secukinumab, } \\
2015\end{array}$ & Cosentyx $^{\circledR}$ & PsO, PsA, AS, nr-axSpA & $\begin{array}{l}300 \mathrm{mg} S \mathrm{~S} \text { at weeks } \\
0,1,2,3,4, \text { then } 300 \mathrm{mg} \\
\mathrm{SC} \mathrm{q} 4 \mathrm{w}\end{array}$ & $\begin{array}{l}\text { Low body weight and } \\
\text { minimal disease } \\
\text { severity: } 150 \mathrm{mg} \\
\text { maintenance } \mathrm{q} 4 \mathrm{w}\end{array}$ & $\begin{array}{l}\text { Dedicated studies for treatment of } \\
\text { scalp psoriasis, nail psoriasis, } \\
\text { palmoplantar psoriasis and axial } \\
\text { psoriatic arthritis }\end{array}$ \\
\hline $\begin{array}{l}\text { Brodalumab, } \\
2017\end{array}$ & Siliq ${ }^{\circledR}$ & $\mathrm{PsO}$ & $\begin{array}{l}210 \mathrm{mg} \mathrm{SC} \text { at weeks } \\
0,1 \text { and } 2 \text {, then } \\
210 \mathrm{mg} \mathrm{SC} \mathrm{q2w}\end{array}$ & & $\begin{array}{l}\text { Frequently succeeds among } \\
\text { patients who failed other biologics } \\
\text { including other IL- I } 7 \text { agents }\end{array}$ \\
\hline $\begin{array}{l}\text { Ixekizumab, } \\
2017\end{array}$ & Taltz $^{\circledR}$ & $\begin{array}{l}\text { PsO, PsA, AS, nr-axSpA, } \\
\text { Pediatric PsO }\end{array}$ & $\begin{array}{l}160 \mathrm{mg} S C \text { at week } 0, \\
80 \mathrm{mg} \text { at week } \\
2,4,6,8,10,12, \text { then } \\
80 \mathrm{mg} \mathrm{SC} \mathrm{q4w}\end{array}$ & $\begin{array}{l}\text { Maintain treatment } \\
\text { response: } 80 \mathrm{mg} \mathrm{SC} \\
\mathrm{q} 2 \mathrm{w}\end{array}$ & $\begin{array}{l}\text { Only biologic agent FDA approved } \\
\text { for treatment of genital psoriasis }\end{array}$ \\
\hline Bimekizumab & $\mathrm{N} / \mathrm{A}$ & & & & Pending FDA Approval \\
\hline \multicolumn{6}{|c|}{ IL-23 inhibitors } \\
\hline $\begin{array}{l}\text { Guselkumab, } \\
2017\end{array}$ & Tremfya $^{\circledR}$ & PsO, PsA & $\begin{array}{l}100 \mathrm{mg} \text { SC at week } 0 \\
\text { and } 4 \text {, then } 100 \mathrm{mg} \\
\mathrm{q} 8 \mathrm{w}\end{array}$ & & $\begin{array}{l}\text { Only IL-23 agent FDA approved for } \\
\text { PsA }\end{array}$ \\
\hline $\begin{array}{l}\text { Tildrakizumab, } \\
2018\end{array}$ & Ilumya ${ }^{\circledR}$ & $\mathrm{PsO}$ & $\begin{array}{l}100 \mathrm{mg} \text { at week } 0 \text { and } \\
4, \text { then } 100 \mathrm{mg} \mathrm{SC} \\
\mathrm{q} 12 \mathrm{w}\end{array}$ & & $\begin{array}{l}\text { Only biologic for PsO covered by } \\
\text { Medicare part B }\end{array}$ \\
\hline $\begin{array}{l}\text { Risankizumab, } \\
2019\end{array}$ & Skyrizi $^{\circledR}$ & $\mathrm{PsO}$ & $\begin{array}{l}150 \mathrm{mg} \text { SC at week } 0 \\
\text { and } 4 \text {, then } 150 \mathrm{mg} \\
\mathrm{q} / 2 \mathrm{w}\end{array}$ & & $\begin{array}{l}\text { Very high efficacy, durability and } \\
\text { rapid onset of action }\end{array}$ \\
\hline Mirikizumab & $\mathrm{N} / \mathrm{A}$ & & & & Pending FDA Approval \\
\hline
\end{tabular}

(Continued) 
Table I (Continued).

\begin{tabular}{|c|c|c|c|c|c|}
\hline $\begin{array}{l}\text { Medication, } \\
\text { Year of FDA } \\
\text { Approval }\end{array}$ & $\begin{array}{l}\text { Brand } \\
\text { Name }\end{array}$ & FDA Approved for & Dosing Regimen & $\begin{array}{l}\text { Alternative Dosing } \\
\text { Regimen }\end{array}$ & Key Merit \\
\hline \multicolumn{6}{|c|}{ IL-I 2/23 inhibitor } \\
\hline $\begin{array}{l}\text { Ustekinumab, } \\
2009\end{array}$ & Stelara ${ }^{\circledR}$ & $\begin{array}{l}\text { PsO, PsA, CD, UC, } \\
\text { Pediatric PsO }\end{array}$ & 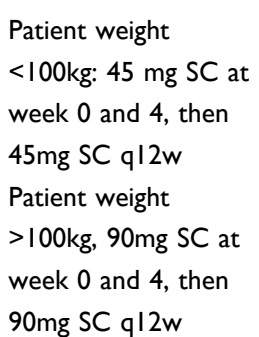 & $\begin{array}{l}\text { Pediatric patient } \\
\text { weight <60kg: weight- } \\
\text { based dose of } 0.75 \mathrm{mg} / \\
\mathrm{kg} \\
\text { Patient weight } 60- \\
100 \mathrm{~kg}, 45 \mathrm{mg} \mathrm{SC} \\
\text { Patient weight } \\
>100 \mathrm{~kg}, 90 \mathrm{mg} \mathrm{SC}\end{array}$ & $\begin{array}{l}\text { Higher dose FDA approved for } \\
\text { patients with larger weight }\end{array}$ \\
\hline
\end{tabular}

Abbreviations: RA, rheumatoid arthritis; PsO, plaque psoriasis; PsA, psoriatic arthritis; AS, ankylosing spondylitis; CD, Crohn's disease; UC, ulcerative colitis; HS, hidradenitis suppurativa; JIA, juvenile idiopathic arthritis; nr-axSpA, non-radiographic axial spondyloarthritis.

TNF with both of its cell-surface receptors, with high affinity and specificity. For over 20 years, adalimumab has been used worldwide in more than 1 million patients for 10 different indications which are: rheumatoid arthritis, juvenile idiopathic arthritis, psoriatic arthritis, ankylosing spondylitis, adult Crohn's disease, pediatric Crohn's disease, ulcerative colitis, plaque psoriasis, hidradenitis suppurativa and uveitis. It is considered to be one of the most effective treatments for psoriatic arthritis with its inhibition of joint destruction and nail psoriasis, even if the patient does not have generalized BSA greater than $10 \%{ }^{7}$ The FDA has also approved the use of adalimumab for juvenile idiopathic arthritis (JIA) in pediatric patients under the age of 2 and for hidradenitis suppurativa (HS) in adolescents. Recently, it has also been approved for the treatment of severe chronic plaque psoriasis in children.

The approved loading dosing of adalimumab for psoriasis in adults is $80 \mathrm{mg}$ given SC at week 0 and $40 \mathrm{mg}$ at week 1 followed by $40 \mathrm{mg}$ given SC every 2 weeks thereafter as the maintenance. The effect of adalimumab appears to decrease over time with more injections than with the newer agents. It is also now available in a citrate-free vehicle, which contains half the volume and uses a smaller needle, resulting in less pain. ESPIRIT Long Term Registry Data shows 10 years of safety data with no new safety signals and low number of events of interest (serious infections, cardiovascular events and malignancy). ${ }^{8}$ PIANO and OTIS registry data show no increased risk with harmful pregnancy outcomes. ${ }^{9}$ Testing for anti-drug antibodies against adalimumab is available to help guide treatment plans. Black box warnings for adalimumab include possible increased risk of tuberculosis and nonmelanoma skin cancer in fair-skinned individuals.
Adalimumab is still considered one of the best first-line agents for treating psoriatic arthritis.

\section{Certolizumab Pegol $\left(\right.$ Cimzia $\left.^{\circledR}\right)$}

Certolizumab (CZP) is a monovalent, humanized Fab antibody fragment, conjugated to a polyethylene glycol (PEG) that inhibits TNF-alpha in a dose-dependent manner. This gives CZP a unique structure amongst all other biologics. There are 6 indications: Crohn's disease, rheumatoid arthritis, psoriatic arthritis, ankylosing spondylitis, nonradiographic axial spondyloarthritis, and moderate-tosevere plaque psoriasis, with up to 7 years of safety follow up with continued treatment with CZP in Crohn's disease. Approved dosing is $400 \mathrm{mg}$ SC every 2 weeks for patients over $90 \mathrm{~kg}$ with no loading dose required. For patients who weigh less than $90 \mathrm{~kg}$, the loading dose is $400 \mathrm{mg}$ at weeks 0,2 , and 4 and then $200 \mathrm{mg}$ SC every 2 weeks. As with other anti-TNF agents, it is recognized by the American College of Rheumatology as one of the firstline treatments of psoriatic arthritis because of its FDA approval for inhibition of joint destruction and bone erosion. CZP's efficacy in treating psoriatic arthritis was maintained over 4 years, in patients both with and without prior anti-TNF exposure. ${ }^{10}$ In Phase III studies, $81.6 \%$ of patients on CZP were able to achieve PASI 75 by week 16, which makes it more effective compared to other TNFalpha inhibitors. ${ }^{11}$ One major advantage of this drug is for use in pregnant or nursing patients. The effects of CZP have been studied in pregnancy and it was found to have minimal transfer across the placenta and into breast milk in two different pharmacokinetic studies ${ }^{12,13}$ (Figure 1). CZP currently has less long-term safety data for the 


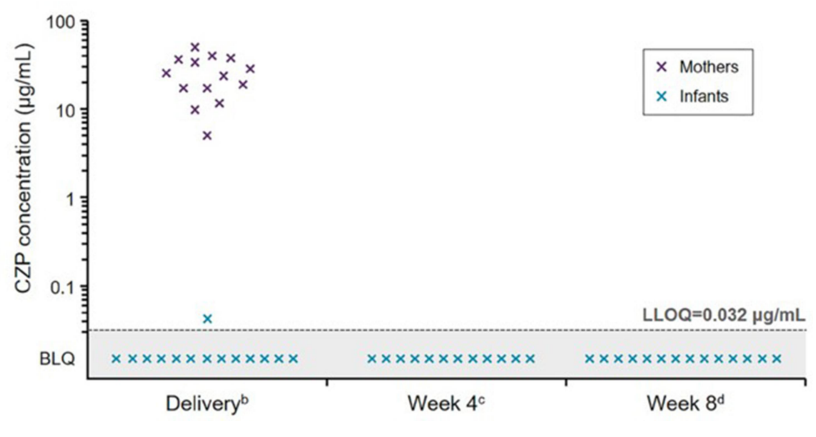

Figure I Plasma certolizumab concentrations in mothers and infants b. Infant samples were collected within 24 hours post-delivery, while mother samples could be collected within 24 hours before or after delivery; c. \pm 7 days (two samples missing); d. \pm 7 days.

Notes: Reprinted from Lack of placental transfer of certolizumab pegol during pregnancy: results from CRIB, a prospective, postmarketing, pharmacokinetic study; Mariette X, Förger F, Abraham B, et al, volume 77(2). Copyright @ 2018, with permission from BMJ Publishing Group Ltd. ${ }^{13}$

treatment of moderate-to-severe plaque psoriasis compared with other agents; the longest safety data available is 3 years. It requires more injections than newer biologic agents.

\section{Infliximab (Remicade ${ }^{\circledR}$ )}

Infliximab is a chimeric monoclonal antibody comprised of a mouse variable region and a human IgG1-alpha constant region which exerts its neutralizing action by binding to both soluble and transmembrane TNF-alpha molecules. ${ }^{14}$ It is approved in adults for the treatment of psoriasis, psoriatic arthritis, rheumatoid arthritis and ankylosing spondylitis. It is also approved for the treatment of Crohn's disease and ulcerative colitis in both adults and children. It will not be discussed further as this medication is administered intravenously and is rarely used by US dermatologists.

\section{IL I 2/23 Agents Ustekinumab (Stelara ${ }^{\circledR}$ )}

Ustekinumab is a human monoclonal antibody that binds with high specificity and affinity to the p40 subunit of both interleukin 12 (IL-12) and IL-23, and as a result, suppresses both IL-12 and IL-23 mediated inflammation which causes psoriasis. ${ }^{15}$ The dose of ustekinumab depends on the patient's age and patient's weight, as the medication is FDA approved in the pediatric and adolescent population. For an adult weighing less than $100 \mathrm{~kg}$, a loading dose of $45 \mathrm{mg}$ administered subcutaneously (SC) at weeks 0 and 4 is then followed by a maintenance dose of $45 \mathrm{mg} \mathrm{SC}$ every 12 weeks. If an adult patient weighs more than $100 \mathrm{~kg}$, a loading dose of $90 \mathrm{mg}$ administered sub-cutaneously (SC) at weeks 0 and 4 is then followed by a maintenance dose of $90 \mathrm{mg}$ SC every 12 weeks. For pediatric and adolescent patients, the dosing frequency also remains unchanged. If the patient weighs less than $60 \mathrm{~kg}$, a weight-based dose of $0.75 \mathrm{mg} / \mathrm{kg}$ is used. If the patient is between 60 and $100 \mathrm{~kg}$ then $45 \mathrm{mg}$ is given. If the patient weighs greater than $100 \mathrm{~kg}$, the dose is $90 \mathrm{mg}$. In summary, for pediatric and adolescent patients, the frequency of dosing is unchanged and a weight-based dosing regimen is used only for patients weighing less than $60 \mathrm{~kg}$.

Ustekinumab has a strong safety profile in that it has more than 20 years of safety data with no evidenced based increase in side effects. There is no evidence for increased risk of tuberculosis. In the USA, it has a pediatric indication down to 6 years of age. The dose is able to be adjusted according to the patient's weight. This is unique in that the practitioner can give a higher dose to someone with a larger body weight, which cannot be done with other biologic agents. It also has the least injections of all biologic agents available (along with risankizumab and tildrakizumab) which is only 4 injections per year of the maintenance dose. Ustekinumab is FDA approved for psoriatic arthritis and inflammatory bowel disease. It is the only IL $12 / 23$ or IL 23 biologic agent with FDA approval for both Crohn's disease and ulcerative colitis. In the treatment of inflammatory bowel disease with ustekinumab, a starting dose as high as $520 \mathrm{mg}$ intravenously is given initially for anybody who weighs $85 \mathrm{~kg}$ or more. This dose is followed by $90 \mathrm{mg}$ SC every 8 weeks. This dosing regimen is used routinely with no significant added safety concerns given the much higher dosage used.

Ustekinumab is less efficacious than newer biologic agents. Furthermore, some patients might experience some worsening of psoriasis in the third month prior to the subsequent injection. These patients may benefit from an increased frequency of dosing, for example to every 8 weeks (which is officially approved in Canada) or an increase in the dosage of the medication to $90 \mathrm{mg}$. While this medication is FDA approved for the treatment of psoriatic arthritis, it is not sanctioned by the FDA regarding inhibition of joint destruction or bone erosion. However, on the Canadian and European labels, ustekinumab does have approval for inhibition of joint destruction and bone erosion in the treatment of psoriatic arthritis. Even though it is not approved by the US FDA for inhibition of joint destruction or bone erosion, data from an integrated analysis of radiographic data from Phase III, multi-center, randomized, doubleblind, placebo-controlled, PSUMMIT-1 and PSUMMIT-2 trials shows that ustekinumab $45 \mathrm{mg}$ and $90 \mathrm{mg}$ significantly 
inhibited radiographic progression of joint damage in patients with active psoriatic arthritis. ${ }^{16}$

\section{IL-I 7 Agents Brodalumab (Siliq ${ }^{\circledR}$ )}

Brodalumab is a human monoclonal antibody that binds the IL-17 receptor A and blocks the biologic activities of IL-17A, IL-17F, IL-17A/F and IL-17E (also known as IL-25). This is a unique mechanism of action as it is the only biologic in its class which blocks the entire IL-17 receptor. It is indicated for the treatment of moderate-to-severe plaque psoriasis in adult patients. The loading dose is $210 \mathrm{mg}$ given $\mathrm{SC}$ at weeks 0,1 and 2. This is followed by a maintenance dose of $210 \mathrm{mg} \mathrm{SC}$ every 2 weeks. Brodalumab has a very high efficacy and very rapid onset of action. In terms of efficacy, $44 \%$ of patients achieved PASI 100 by week 12 in the Phase III clinical trials. The very rapid onset of action reaches statistical significance for PASI 90 at week 2 and PASI 100 at week 4 all versus ustekinumab. There are data for rescue from failure of other biologic agents and it is indicated for patients who have failed to respond or lost response to other systemic therapies. This medication frequently succeeds among patients who failed other biologics including other IL-17 agents. ${ }^{17}$ After 52 weeks of treatment, less than $3 \%$ of patients developed antibodies to brodalumab and none of them were neutralizing. There is no convincing scientific evidence of increased risk of tuberculosis and recent one-year pharmacovigilance data published in August 2020 showed no new completed suicides or suicide attempts, no new-onset cases of inflammatory bowel disease or no new major adverse cardiac events. ${ }^{18}$ Given its significantly lower treatment costs and high PASI rates, brodalumab has been shown to be the most cost-effective agent for the treatment of moderate-to-severe psoriasis (Figure 2). ${ }^{19}$ There is even data on cost-effectiveness from a competitor drug company supporting this claim. ${ }^{20}$

Unfortunately, brodalumab has a black box warning for suicide. However, during worldwide phase III clinical trials, only 3 completed suicides occurred in 2 out of 390 research sites out of 4464 subjects. During these trials, patients were not excluded for history of suicidal ideation/behavior or drug and alcohol history, unlike other studies. There is no suicide warning in any other country for this medication except in the US. Furthermore, there is no scientific evidence for an increased risk of suicide with this medication. ${ }^{21}$ Like other IL-17 agents there is an increased concern for risk of new or worsening inflammatory bowel disease or slight increase in risk of fungal or yeast infections. The incidence of new-onset IBD is 1 out of

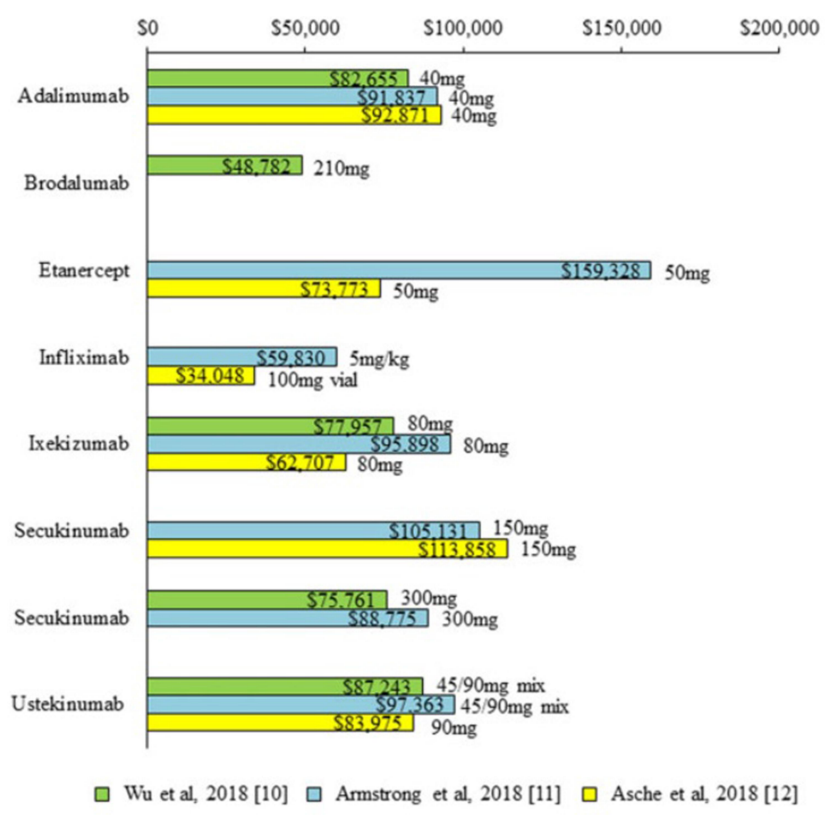

Figure 2 Annual treatment costs per PASI 75. PASI indicates Psoriasis Area and Severity Index.

Notes: Reprinted from Feldman SR, Wu JJ, Armstrong AW, et al. Journal of Psoriasis and Psoriatic Arthritis, 2019; volume 4(3), pages 133-142. Copyright () 2019, () SAGE Publications. ${ }^{19}$

4464 patients on brodalumab. The risk of candida infection is $0.9 \%$ for brodalumab vs $0.2 \%$ in placebo.

\section{Secukinumab (Cosentyx ${ }^{\circledR}$ )}

Secukinumab is a fully human G1k monoclonal antibody, which selectively binds and inhibits IL-17A. ${ }^{22}$ It is currently FDA approved for plaque psoriasis, ankylosing spondylitis, psoriatic arthritis, and active non-radiographic axial spondyloarthritis. Dosing of secukinumab for the treatment of psoriasis starts with a loading dose of $300 \mathrm{mg}$ given SC at weeks 0 , $1,2,3$, and 4 , followed by a maintenance dose of $300 \mathrm{mg} \mathrm{SC}$ every 4 weeks. In patients with lower body weight and minimal disease severity, $150 \mathrm{mg}$ may be acceptable for maintenance dosing. For patients who may need higher doses, such as those with resistant disease and/or higher BMI, published data show a possible benefit of increasing dosing of secukinumab to 300mg SC every 2 weeks during maintenance. Higher dosing resulted in numerically superior efficacy, but due to size of the study, the difference was not statistically significant.

Secukinumab has excellent efficacy in the treatment of several disease domains. Dedicated studies for difficult to treat areas such as scalp, nail and palmoplantar psoriasis have been completed with data showing sustained efficacy for greater than 2 years for the latter two conditions. ${ }^{23-25}$ Secukinumab possesses higher efficacy versus several 
other subcutaneous biologic agents, showing superiority in head-to-head trials against both etanercept and ustekinumab (Figure 3). ${ }^{26}$ It also is the only biologic with a study showing efficacy for the treatment of axial psoriatic arthritis. Additionally, it has been recognized by the FDA for its efficacy in inhibiting psoriatic joint destruction, making it a better choice vs. an IL-23 or IL 12/23 agent for the treatment of psoriatic arthritis. ${ }^{27}$

Along with its exceptional clinical efficacy, it also has an extremely high recapture rate. After abrupt discontinuation of the drug and subsequent flare, restarting secukinumab led to $95 \%$ of patients achieving PASI 75 by week 12 .

Secukinumab has the longest track record for safety in realworld usage out of all the IL-17 inhibitors and no black box safety warnings. ${ }^{28}$ It is one of the best tolerated biologic injectables in terms of injection site reactions and pain. While there is an already established association of increased reactivation and onset of tuberculosis risk in some biologics, particularly with TNF-alpha inhibitors, no study to date has found evidence of an increased tuberculosis risk in secukinumab.

There are very few adverse reactions of concern associated with secukinumab. Patients using secukinumab

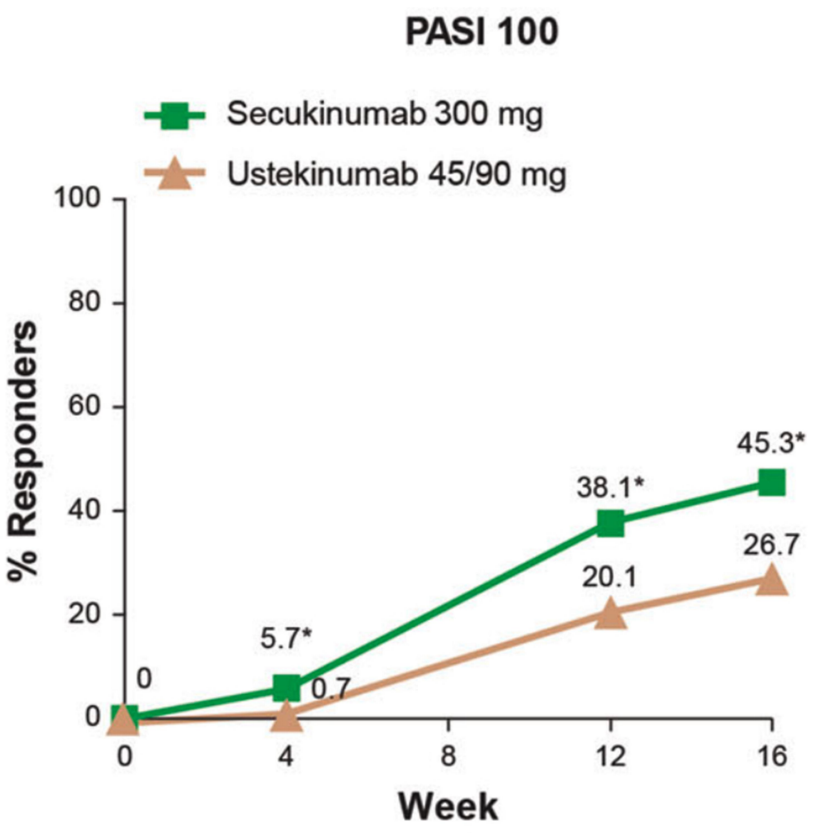

Figure 3 Clear skin responses (PASI 100) was greater among secukinumab treated patients compared to ustekinumab at every time point from week 4 out to week 16 in the CLARITY study. ${ }^{*} \mathrm{p}<0.0001$.

Notes: Reproduced from Bagel J, Nia J, Hashim PW, et al. Secukinumab is Superior to Ustekinumab in Clearing Skin in Patients with Moderate to Severe Plaque Psoriasis (16-Week CLARITY Results). Dermatol Ther (Heidelb). 2018;8(4):57I-579. Copyright $\left(2018\right.$, Springer-Verlag GmbH Germany, part of Springer Naturek. ${ }^{26}$ were found to have a mild increase in superficial fungal and yeast infections. Fungal rates in a phase III study for secukinumab, while increased over placebo, were less than $1 \%$. Mucocutaneous candidiasis in the secukinumab treatment group was $1.2 \%$ vs. $0.3 \%$ placebo. Additionally, studies show an increased risk of inflammatory bowel disease (IBD); however, the incidence of new-onset IBD is less than 1 out of 1000 patients on secukinumab.

\section{Ixekizumab $\left(\right.$ Taltz $\left.^{\circledR}\right)$}

Ixekizumab is a high-affinity, humanized IgG4 monoclonal antibody for IL-17A, inhibiting interaction with the IL-17 receptor. FDA indications for ixekizumab include plaque psoriasis, psoriatic arthritis, ankylosing spondylitis, and non-radiographic axial spondyloarthritis. The loading dose is $160 \mathrm{mg} \mathrm{SC}$ at week 0 and subsequent doses of $80 \mathrm{mg}$ at weeks 2, 4, 6, 8, 10, and 12. Maintenance dosing is continued at $80 \mathrm{mg} \mathrm{SC}$ every 4 weeks. To maintain response to treatment, practitioners can consider increasing the dosing regimen to $80 \mathrm{mg} \mathrm{SC}$ every 2 weeks. It is the only biologic with data and FDA labeling specifically for genital plaque psoriasis. Also, ixekizumab is the only IL-17 agent that is FDA approved for treatment of plaque psoriasis down to the age of 6 years old. Ixekizumab was shown to be superior to placebo in the treatment of moderate-to-severe pediatric psoriasis, and the safety profile was generally consistent with that observed in adults. $^{29}$

Ixekizumab has very high efficacy as demonstrated through a PASI 75 achievement in $90 \%$ of patients by week 12. Efficacy data points to ixekizumab as being the fastest acting biologic. Head-to-head comparison showed a faster onset of action than guselkumab in the treatment of plaque psoriasis (Figure 4). ${ }^{30}$ In headto-head studies against adalimumab for treatment of psoriatic arthritis, both biologics were found to have similar symptom control and inhibition of joint destruction and bone erosion. ${ }^{31}$ Additionally, when both PASI 100 rates and psoriatic arthritis improvement results were combined, ixekizumab was superior to adalimumab.

Ixekizumab is a well-tolerated biologic with minimal adverse events. It has no black box safety warnings and no evidence of increased tuberculosis risk. Of note, there is a higher rate of injection site pain and reaction, but during phase III studies $97 \%$ of patients with a reaction did not find it 


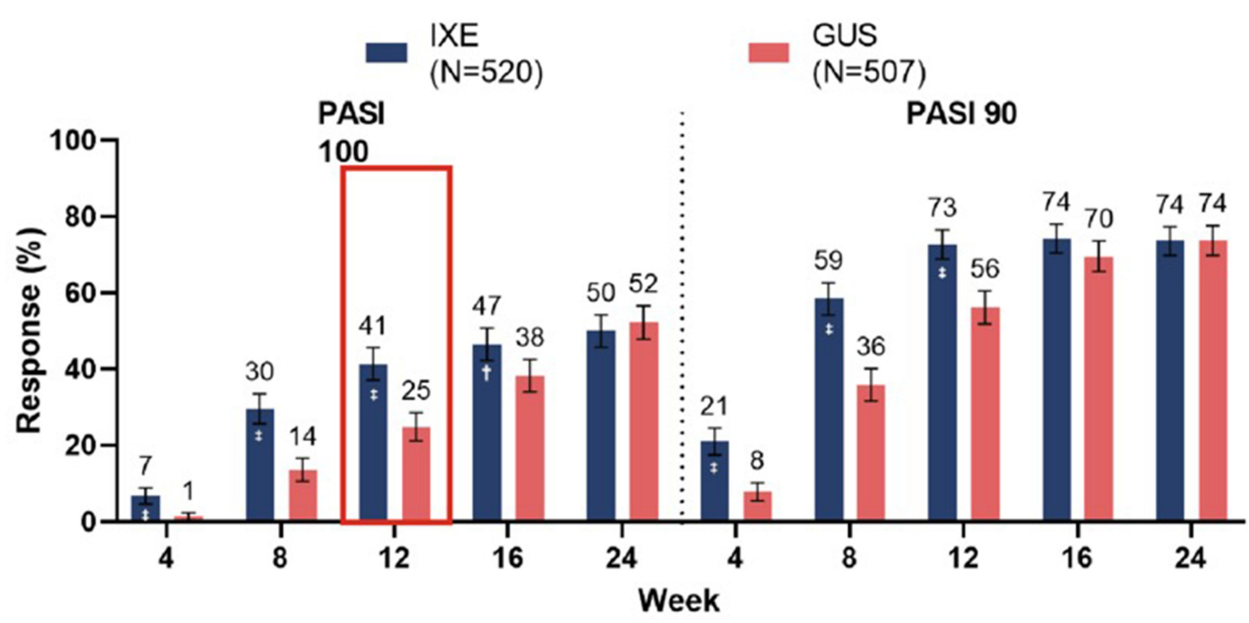

Figure 4 Head-to-head comparison showed faster onset of action for ixekizumab vs guselkumab in the treatment of plaque psoriasis. The red box indicates the primary endpoint for the study.

Notes: Reproduced from Blauvelt et. al. Ixekizumab vs. Guselkuamb: 24 week clinical responses and 4-week gene expression data. Oral presentation presented at the: Maui Derm; June 2020; Virtual Congress. ${ }^{30}$

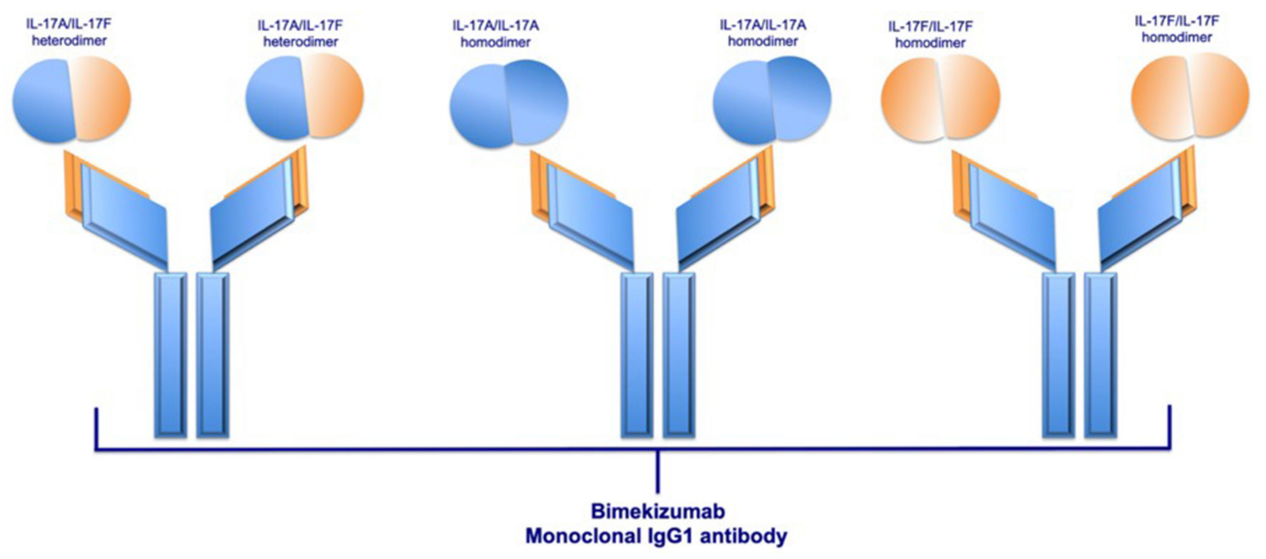

Figure 5 Schematic structure of bimekizumab and its binding sites: IL-I7A/IL-I7F heterodimers, IL-17A/IL-17A homodimers, and IL-I7F-IL-I7F homodimers. Notes: Reprinted from Blauvelt A, Chiricozzi A, Ehst BD. Bimekizumab,Current Dermatology Reports. Copyright 2020, with permission from Springer Nature. ${ }^{34}$

significant enough to discontinue the study. Injection site reaction was actually noted to improve over the course of treatment. $^{32}$ There is also a concern of increased risk of IBD, however, the incidence of new-onset IBD is less than 1 out of 1000 patients on ixekizumab. Studies showed a slight increase in superficial fungal and yeast infections, although the candida rate in phase III studies is still less than $0.6 \%$ while on the once every 4 weeks dosing regimen versus $0.5 \%$ on placebo. ${ }^{33}$

\section{Bimekizumab}

Bimekizumab is a novel $\operatorname{IgG}$ monoclonal antibody that binds to a peptide region that is shared by IL-17A and IL17F (Figure 5). ${ }^{34}$ Data from the BE VIVID clinical trials demonstrated superior levels of clinical response with bimekizumab compared with ustekinumab. ${ }^{35}$ At week 16, 85\% of patients in the bimekizumab group achieved a PASI 90 versus $49.7 \%$ of patients on ustekinumab. ${ }^{35}$ After one dose, faster onset of response was observed with bimekizumab compared with ustekinumab where, at week $4,76.9 \%$ of patients in the bimekizumab group achieved PASI 75 versus $15.3 \%$ in the ustekinumab group. ${ }^{35}$ Clinical responses with bimekizumab were durable through week 52 where, at week 52, PASI 90 was achieved in $81.6 \%$ of bimekizumab patients versus $55.8 \%$ of ustekinumab patients. Data from the BE READY trial showed a high level of skin clearance with bimekizumab after one dose with $75.9 \%$ of patients achieving PASI 75 versus $1.2 \%$ of placebo patients. ${ }^{36}$ It is not yet approved by the FDA for treatment of plaque psoriasis and the results from the phase III study are still pending. 
Loss of $\mathbf{2 5 0 \%}$ of Achieved PASI Improvement

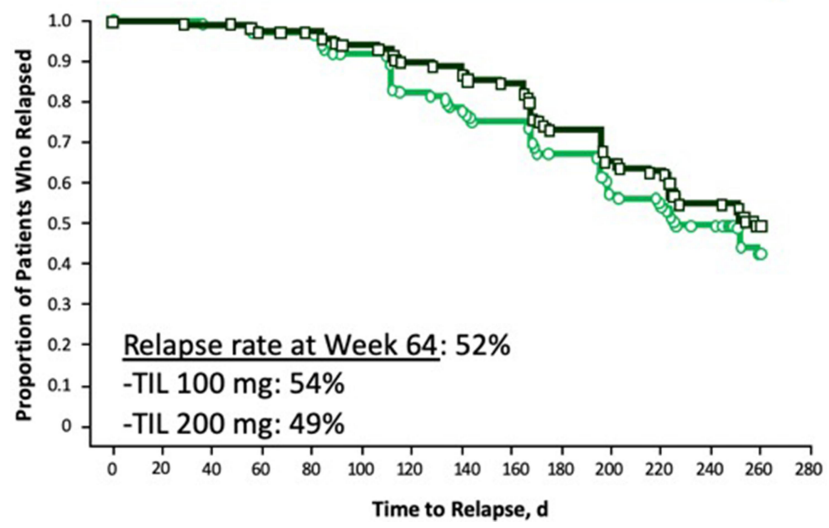

Figure 6 Relapse rates in reSURFACE I study in patients re-randomized to placebo at week 28.

Notes: Reproduced from Thaçi Iversen L, Pau-Charles I, Rozzo S, Blauvelt A, Reich $K$. Long-term efficacy and safety of tildrakizumab in patients with moderate-tosevere psoriasis who were responders at week 28: pooled analysis through 3 years (I48 weeks) from reSURFACE I and reSURFACE 2 phase 3 trials. Oral presentation presented at the: 27th European Academy of Dermatology and Venereology (EADV) Congress; September 2018; Paris, France. ${ }^{38}$

\section{IL-23 Agents}

\section{Tildrakizumab (llumya ${ }^{\circledR}$ )}

Tildrakizumab is a humanized IgG1, monoclonal antibody designed to selectively block IL-23 by binding to the p19 subunit. The loading dose is $100 \mathrm{mg}$ at week 0 and week 4 . This is followed by a maintenance dose of $100 \mathrm{mg}$ every 12 weeks. Tildrakizumab is only FDA approved for moderate to severe plaque psoriasis. However, it is the only biologic for psoriasis guaranteed to be covered by Medicare part B, which is the hospital benefit. Most biologics are usually covered through Medicare part $\mathrm{D}$, which is the prescription part where the "donut hole" exists meaning the patient may be required to provide a large co-pay for the medication. As a result of this, it is the only biologic where injection is required to be given by the provider (not self-injection). It is only 4 injections per year for the maintenance dose which makes a provider dosing regimen reasonable for the provider. Tildrakizumab has a very high recapture rate where 85.7-$96.1 \%$ of patients will regain response (PASI 75) after retreatment. ${ }^{37}$ It also has a long "time to relapse" duration. It took a median of 7.4 months, for PASI 75 responders, to lose half of their best response (Figure 6) ${ }^{38}$ In a post hoc analysis of phase III reSURFACE 1 trial, a large proportion (46\%) of tildrakizumab $100 \mathrm{mg}$ responders did not relapse (defined as a reduction in maximum PASI response by greater than or equal to $50 \%$ ) after re-randomization to placebo 48 weeks after receiving last dose of drug. ${ }^{39}$ Tildrakizumab has a very safe biologic profile. According to the package insert (Tildrakizumab [package insert]. Princeton, NJ: Sun Pharmaceuticals, Inc.), this medication has the least number of adverse events occurring in at least $1 \%$ in phase III trials of all the biologics for psoriasis available (only 3 items - upper respiratory infections, injection site reaction and diarrhea). One disadvantage is that the onset of action is slower than other IL23 agents in that the efficacy peaks slower.

\section{Risankizumab (Skyrizi ${ }^{\circledR}$ )}

Risankizumab is a humanized IgG1 monoclonal antibody selectively targeting the p19 subunit of IL-23. It is administered at a dose of $150 \mathrm{mg}$ (two $75 \mathrm{mg}$ syringes) subcutaneously at week 0 and week 4 , followed by a maintenance dose of $150 \mathrm{mg}$ every 12 weeks. Risankizumab requires only 4 sets of injections per year for maintenance dose (one dose every 3 months). The 2 injection necessity per dose is one of the main issues associated with risankizumab, though one injection delivery is under FDA review. Its only current FDA approved indication is for moderate-to-severe plaque psoriasis in adults.

Risankizumab has been shown to have excellent efficacy in its phase III ULTIMMA-1 and ULTIMMA-2 trial data. Primary endpoints of PASI 90 were achieved in $75.3 \%$ $74.8 \%$ of patients at week 16 and sPGA $0 / 1$ was demonstrated in $88 \%$ and $84 \%$ of patients at week 16 , respectively. In ULTIMMA-1 and ULTIMMA-2, secondary endpoints included PASI 100 in $36 \%$ and $51 \%$ of patients at week 16 , respectively. sPGA 0 was achieved in $37 \%$ and $51 \%$ of patients at week 16 , respectively.

Risankizumab has been shown to have very high efficacy in many comparison trials. It has superior efficacy to adalimumab, ustekinumab, and secukinumab. ${ }^{40-42}$ Though the onset of action is as fast as the IL-17 agent secukinumab, it achieved much better efficacy by week $52 .{ }^{42}$ Additionally, it has been noted to have high durability. ${ }^{43}$ After discontinuation, responders took a mean of 295 days to experience psoriasis recurrence to a level of moderate or worse.

While the long-term safety data available is not as long as the older agents, there is long-term safety data available which demonstrates that risankizumab is safe and well tolerated at 58 months. ${ }^{44}$ In comparison to IL-17 agents, IL-23 agents as a class have no concern regarding increased risk of inflammatory bowel disease, and maybe less increased risk for tinea and candida fungal infections. Furthermore, in the IMMhance phase 3 study, 31 psoriasis patients with untreated latent tuberculosis infection who were treated with risankizumab did not experience tuberculosis reactivation (Risankizumab [Package Insert]. North 
Chicago IL: Abbive Inc.; 2019). The most common adverse reactions include upper respiratory infection, headache, fatigue, injection site reactions, and tinea infections.

\section{Guselkumab (Tremfya ${ }^{\circledR}$ )}

Guselkumab is a fully human $\operatorname{IgG} 1 \lambda$ monoclonal antibody which inhibits the p19 subunit of interleukin 23 (IL-23). FDA approved indications for guselkumab include moderate-to-severe plaque psoriasis and psoriatic arthritis. It is administered at a loading dose of $100 \mathrm{mg} \mathrm{SC}$ at week 0 and week 4 , followed by a maintenance dose of $100 \mathrm{mg}$ every 8 weeks. It also has a convenient delivery system; drug administration is performed by an auto injector (OnePress Injector) which causes patients less pain because patients can control the rate of injection.

Guselkumab has very high efficacy with $90 \%$ of patients achieving PASI 75 by week 16. In the VOYAGE 1 trial, the primary endpoint of PASI 90 was achieved in $73 \%$ of patients at week $16 .{ }^{45}$

In the ECLIPSE study, guselkumab was superior secukinumab in PASI 90 efficacy at week $48 .{ }^{46}$ In addition, demonstrating superiority in every endpoint in comparison to adalimumab for plaque psoriasis, guselkumab was shown to be superior in efficacy for scalp and palmoplantar psoriasis. ${ }^{47}$ Results were similar between these two agents for nail psoriasis. Guselkumab is approved by the Japanese regulatory agency for palmoplantar pustulosis. While the onset of action is slower than ixekizumab in a head-tohead comparison, the week 24 efficacy endpoints were similar. It is the only IL-23 FDA approved for psoriatic arthritis.

The safety profile of guselkumab is excellent with over 3 years of safety data. There is no convincing scientific evidence of increased tuberculosis risk. There are no FDA warnings of increased risk of superficial tinea or candida infections in the package insert, in the warning and precautions section. No concerns to date have been raised about the risk of inflammatory bowel disease.

\section{Mirikizumab}

Mirikizumab is an investigational humanized IgG4 monoclonal antibody that binds to the p19-subunit of IL-23. Data from Phase II trials have shown that at week $16,67 \%$ of patients achieved PASI 90 with $300 \mathrm{mg}$ of mirikizumab every 8 weeks. The most common adverse events (occurring in at least three patients) were viral and upper respiratory tract infections, injection-site pain, hypertension and diarrhea. ${ }^{48}$ Phase II data, with results from 104 weeks, have also shown that many patients who do not achieve PASI 90/100 during the initial 16 weeks of treatment with mirikizumab can attain and maintain high-level responses with continued treatment and that responders during the initial 16 weeks can maintain highlevel response with as needed treatment. ${ }^{49}$ It is not yet approved by the FDA for the treatment of plaque psoriasis.

\section{Discussion}

This manuscript reviews the most relevant facts about every biologic agent available for the treatment of psoriasis with a special focus on the merits and demerits of each agent. After reviewing all the available options, it has become clear that each of these agents has their own unique merits. Therefore, the more simplistic idea that several of the older biologic agents available are obsolete may not be true. In practice, the different variations in clinical challenges faced by the provider are vast. Given this, a biologic agent thought to be outdated may turn out to be the best agent for a particular patient. For example, some providers now think that etanercept, which was FDA approved for psoriasis in 2004, is no longer worth considering because of its limited efficacy. However, it is good to remember that etanercept has one of the best FDA "geriatric statements" attesting to its safety in older patients, stating essentially that the risk for elderly patients is nearly the same as the risk for younger patients. Other biologic agents either state the opposite (i.e., older patients are at greater risk than younger patients, such as adalimumab) or have no geriatric statement because of lack of data in this population.

Another example is certolizumab, which is also an older agent with more than 20 years of use. This agent can easily be forgotten with the assumption that it probably has no better efficacy than other older biologic agents for psoriasis. In reality, the PASI 75 achievement rate of certolizumab approaches that of the newer IL-17 agents. Moreover, being an anti-TNF biologic, its efficacy for psoriatic arthritis is one of the best given its high performance for the treatment of psoriatic arthritis, which may not be matched by the newest IL-23 agents.

Lastly, some clinicians may dismiss tildrakizumab as just another IL-23 agent, with a slower onset of action and no further advantages in clinical efficacy. However, on close examination, tildrakizumab turns out to be the only biologic agent guaranteed to be covered by Medicare part B due to the requirement that this agent has to be administered by the provider. Moreover, tildrakizumab has the smallest list of adverse events (occurring in at least $1 \%$ of subjects) in phase III clinical trials. Therefore, clinicians who are most interested 
in safety may find this fact highly useful, especially in elderly Medicare patients.

Therefore, the recommendation of the authors is not to dismiss any biologic agents currently available based on just superficial assessments or a cursory glance. The authors hope that this complete characterization of all the biologic agents used by dermatologists for psoriasis proves helpful in understanding the nuanced differences between the agents, which could prove to be very important in improving patient care and patient satisfaction.

\section{Disclosure}

Wilson Liao reports grants from Amgen, Novartis, Janssen, Leo Pharma, Sanofi, TRex Bio, and Regeneron. Tina Bhutani is currently an investigator for Abbvie, Galderma, Pfizer and Regeneron. She has served as an advisor for Abbvie, Boehringer-Ingelheim, Bristol-Myers-Squibb, Clarify, Leo, Lilly, Novartis, Pfizer and Sun Pharma. John Koo reports being a speaker and adviser for Amgen, Abbvie, Eli Lilly, Sun Pharmaceutical, Novartis, Ortho Dermatologic, Janssen and UCB. The authors report no other potential conflicts of interest for this work.

\section{References}

1. Armstrong AW, Read C. Pathophysiology, clinical presentation, and treatment of psoriasis: a review. JAMA. 2020;323(19):1945-1960. doi:10.1001/jama.2020.4006

2. Alwan W, Nestle FO. Pathogenesis and treatment of psoriasis: exploiting pathophysiological pathways for precision medicine. Clin Exp Rheumatol. 2015;33(5 Suppl 93):S2-S6.

3. Gottlieb AB, Matheson RT, Lowe N, et al. A randomized trial of etanercept as monotherapy for psoriasis. Arch Dermatol. 2003;139 (12):1627-1632; discussion 1632. doi:10.1001/archderm.139.12.1627

4. Tan CS, Koralnik IJ. Progressive multifocal leukoencephalopathy and other disorders caused by JC virus: clinical features and pathogenesis. Lancet Neurol. 2010;9(4):425-437. doi:10.1016/S1474-4422(10)70040-5

5. Gordon K, Korman N, Frankel E, et al. Efficacy of etanercept in an integrated multistudy database of patients with psoriasis. $\mathrm{J} \mathrm{Am} \mathrm{Acad}$ Dermatol. 2006;54(Suppl 3):S101-S111. doi:10.1016/j.jaad.2005.11.1088

6. Leonardi CL, Powers JL, Matheson RT, et al. Etanercept as monotherapy in patients with psoriasis. $N$ Engl $J$ Med. 2003;349 (21):2014-2022. doi:10.1056/NEJMoa030409

7. Elewski BE, Baker CS, Crowley JJ, et al. Adalimumab for nail psoriasis: efficacy and safety over 52 weeks from a phase-3, randomized, placebo-controlled trial. J Eur Acad Dermatol Venereol. 2019;33(11):2168-2178. doi:10.1111/jdv.15793

8. Wu JJ, Abramovits W, Valdecantos WC, et al. 10-year interim results from the ESPRIT registry: real-world safety, effectiveness, and patient-reported outcomes of adalimumab for moderate-to-severe psoriasis. Poster presented at the: 28th European Academy of Dermatology and Venereology (EADV) Congress; October 2019; Madrid, Spain; 2020.

9. Mahadevan U, Martin CF, Dubinsky M, Kane SV, Sands BE, Sandborn W. 960 exposure to anti-TNF $\alpha$ therapy in the third trimester of pregnancy is not associated with increased adverse outcomes: results from the PIANO registry | request PDF. Gastroenterology. 2014. doi:10.1016/S0016-5085(14)60602-8
10. Van Der Heijde D, Deodhar A, FitzGerald O, et al. 4-year results from the RAPID-PsA phase 3 randomised placebo-controlled trial of certolizumab pegol in psoriatic arthritis. RMD Open. 2018. doi:10.1136/rmdopen-2017-000582

11. Gottlieb AB, Blauvelt A, Thaçi D, et al. Certolizumab pegol for the treatment of chronic plaque psoriasis: results through 48 weeks from 2 phase 3, multicenter, randomized, double-blinded, placebo-controlled studies (CIMPASI-1 and CIMPASI-2). $J$ Am Acad Dermatol. 2018. doi:10.1016/j.jaad.2018.04.012

12. Clowse ME, Förger F, Hwang C, et al. Minimal to no transfer of certolizumab pegol into breast milk: results from CRADLE, a prospective, postmarketing, multicentre, pharmacokinetic study. Ann Rheum Dis. 2017. doi:10.1136/annrheumdis-2017-211384

13. Mariette X, Förger F, Abraham B, et al. Lack of placental transfer of certolizumab pegol during pregnancy: results from CRIB, a prospective, postmarketing, pharmacokinetic study. Ann Rheum Dis. 2018;77(2):228-233. doi:10.1136/annrheumdis-2017-212196

14. Gottlieb AB, Masud S, Ramamurthi R, et al. Pharmacodynamic and pharmacokinetic response to anti-tumor necrosis factor- $\alpha$ monoclonal antibody (infliximab) treatment of moderate to severe psoriasis vulgaris. $J$ Am Acad Dermatol. 2003;48(1):68-75. doi:10.1067/mjd.2003.10

15. Kauffman CL, Aria N, Toichi E, et al. A phase I study evaluating the safety, pharmacokinetics, and clinical response of a human IL-12 p40 antibody in subjects with plaque psoriasis. J Investig Dermatol. 2004;123(6):1037-1044. doi:10.1111/j.0022-202X.2004.23448.x

16. Kavanaugh A, Ritchlin C, Rahman P, et al. Ustekinumab, an anti-IL-12/23 p40 monoclonal antibody, inhibits radiographic progression in patients with active psoriatic arthritis: results of an integrated analysis of radiographic data from the phase 3, multicentre, randomised, double-blind, placebo-controlled PSUMMIT-1 and PSUMMIT-2 trials. Ann Rheum Dis. 2014;73(6):1000-1006. doi:10.1136/annrheumdis-2013-204741

17. Kimmel G, Chima M, Kim HJ, et al. Brodalumab in the treatment of moderate to severe psoriasis in patients when previous anti-interleukin 17A therapies have failed. $J$ Am Acad Dermatol. 2019;81(3):857-859. doi:10.1016/j.jaad.2019.05.007

18. Lebwohl M, Leonardi C, Wu JJ, et al. One-year pharmacovigilance update of brodalumab. J Drugs Dermatol. 2020;19(8):807-808. doi:10.36849/JDD.2020.5138

19. Feldman SR, Wu JJ, Armstrong AW, et al. Evaluating costs of biologic drugs for the treatment of moderate-to-severe psoriasis in the United States. JPPA. 2019;4(3):133-142. doi:10.1177/2475530319842174

20. Jia X, Zhao Y, Carrico J, et al. Cost-effectiveness of tildrakizumab in U. S. patients with moderate-to-severe plaque psoriasis. $J$ Am Acad Dermatol. 2019;81(4):AB39. doi:10.1016/j.jaad.2019.06.179

21. Brownstone ND, Reddy V, Thibodeaux Q, et al. Brodalumab for treatment-resistant psoriasis: case reports and safety update. JPPA. 2020;5:82-85. doi:10.1177/2475530320925067

22. Blauvelt A. Safety of secukinumab in the treatment of psoriasis. Expert Opin Drug Saf. 2016. doi:10.1080/14740338.2016.1221923

23. Bagel J, Duffin KC, Moore A, et al. The effect of secukinumab on moderate-to-severe scalp psoriasis: results of a 24 -week, randomized, double-blind, placebo-controlled phase $3 \mathrm{~b}$ study. $\mathrm{J} \mathrm{Am}$ Acad Dermatol. 2017;77(4):667-674. doi:10.1016/j.jaad.2017.05.033

24. Reich K, Sullivan J, Arenberger P, et al. Secukinumab shows high and sustained efficacy in nail psoriasis: 2.5-year results from the randomized placebo-controlled TRANSFIGURE study. $\mathrm{Br}$ J Dermatol. 2020. doi:10.1111/bjd.19262

25. Gottlieb AB, Kubanov A, Doorn MV, et al. Sustained efficacy of secukinumab in patients with moderate-to-severe palmoplantar psoriasis: 2.5-year results from GESTURE, a randomized, double-blind, placebocontrolled trial. Br J Dermatol. 2020;182(4):889-899. doi:10.1111/ bjd.18331

26. Bagel J, Nia J, Hashim PW, et al. Secukinumab is superior to ustekinumab in clearing skin in patients with moderate to severe plaque psoriasis (16-week CLARITY results). Dermatol Ther (Heidelb). 2018;8(4):571-579. doi:10.1007/s13555-018-0265-y 
27. Mease P, van der Heijde D, Landewé R, et al. Secukinumab improves active psoriatic arthritis symptoms and inhibits radiographic progression: primary results from the randomised, double-blind, phase III FUTURE 5 study. Ann Rheum Dis. 2018;77(6):890-897. doi:10.1136/annrheumdis-2017-212687

28. Deodhar A, Mease PJ, McInnes IB, et al. Long-term safety of secukinumab in patients with moderate-to-severe plaque psoriasis, psoriatic arthritis, and ankylosing spondylitis: integrated pooled clinical trial and post-marketing surveillance data. Arthritis Res Ther. 2019;21(1):111. doi:10.1186/s13075-019-1882-2

29. Paller AS, Seyger MMB, Magariños GA, et al. Efficacy and safety of ixekizumab in a phase III, randomized, double-blind, placebo-controlled study in paediatric patients with moderate-tosevere plaque psoriasis (IXORA-PEDS). Br J Dermatol. 2020;183 (2):231-241. doi:10.1111/bjd.19147

30. Blauvelt A, Papp KA, Griffiths CE, et al. Ixekizumab vs. Guselkuamb: 24 week clinical responses and 4-week gene expression data. Oral presentation presented at the: Maui Derm; June 2020; Virtual Congress; 2020.

31. Smolen JS, Sebba A, Ruderman E, et al. Op0228 efficacy and safety of ixekizumab versus adalimumab (spirit-H2h) with and without concomitant conventional synthetic disease-modifying antirheumatic drugs (dmard) in biologic dmard-naïve patients with psoriatic arthritis: 52-week results. Ann Rheum Dis. 2020;79(Suppl 10):143-144. doi:10.1136/annrheumdis-2020-eular.4615

32. Shear NH, Paul C, Blauvelt A, et al. Safety and tolerability of ixekizumab: integrated analysis of injection-site reactions from 11 clinical trials. J Drugs Dermatol. 2018;17(2):200-206.

33. Gordon KB, Blauvelt A, Papp KA, et al. Phase 3 trials of ixekizumab in moderate-to-severe plaque psoriasis. $N$ Engl J Med. 2016;375 (4):345-356. doi:10.1056/NEJMoa1512711

34. Blauvelt A, Chiricozzi A, Ehst BD. Bimekizumab. Curr Derm Rep. 2020;9(1):36-42. doi:10.1007/s13671-020-00286-2

35. Reich K, Papp K, Blauvelt A, et al. Efficacy and safety of bimekizumab in patients with moderate-to-severe plaque psoriasis: results from BE VIVID, a 52-week phase 3, randomized, double-blinded, ustekinumab- and placebo-controlled study. Oral presentation presented at the: American Academy of Dermatology (AAD); March 2020; Virtual Conference; 2020.

36. Gordon K, Foley P, Krueger JG, et al. Efficacy and safety of bimekizumab in patients with moderate-to-severe plaque psoriasis: results from BE READY, a 56-week phase 3, randomized, double-blinded, placebo-controlled study with randomized withdrawal. Oral presentation presented at the: American Academy of Dermatology (AAD); March 2020; Virtual Conference; 2020

37. Papp K, Kimball A, Tyring S, et al. Maintenance of treatment response in chronic plaque psoriasis patients continuing treatment or discontinuing treatment with tildrakizumab in a 64-week, randomized controlled, phase 3 trial. J Am Acad Dermatol. 2017;76(6): AB164. doi:10.1016/j.jaad.2017.04.637

38. Thaçi D, Iversen L, Pau-Charles I, Rozzo S, Blauvelt A, Reich K. Long-term efficacy and safety of tildrakizumab in patients with moderate-to-severe psoriasis who were responders at week 28: pooled analysis through 3 years (148 weeks) from reSURFACE 1 and reSURFACE 2 phase 3 trials. Oral presentation presented at the: 27th European Academy of Dermatology and Venereology (EADV) Congress; September 2018; Paris, France; 2018.
39. Cantrell W, Lee P, Mendelsohn AM, Parno J, Rozzo SJ, Liao W. Efficacy and safety of tildrakizumab $100 \mathrm{mg}$ for plaque psoriasis in patients randomized to treatment continuation vs treatment withdrawal with retreatment upon relapse in resurface 1. J Skin. 2020;4(5): s40-s40. doi:10.25251/skin.4.supp.40

40. Reich K, Gooderham M, Thaçi D, et al. Risankizumab compared with adalimumab in patients with moderate-to-severe plaque psoriasis (IMMvent): a randomised, double-blind, active-comparatorcontrolled phase 3 trial. Lancet. 2019;394(10198):576-586. doi:10.1016/S0140-6736(19)30952-3

41. Gordon KB, Strober B, Lebwohl M, et al. Efficacy and safety of risankizumab in moderate-to-severe plaque psoriasis (UltIMMa-1 and UltIMMa-2): results from two double-blind, randomised, placebo-controlled and ustekinumab-controlled phase 3 trials. Lancet. 2018;392(10148):650-661. doi:10.1016/S0140-6736(18) 31713-6

42. Warren RB, Blauvelt A, Poulin Y, et al. Efficacy and safety of risankizumab vs. secukinumab in patients with moderate-to-severe plaque psoriasis (IMMerge): results from a phase III, randomized, open-label, efficacy-assessor-blinded clinical trial. $\mathrm{Br} J$ Dermatol. 2020. doi:10.1111/bjd.19341

43. Blauvelt A, Leonardi CL, Gooderham M, et al. Efficacy and safety of continuous risankizumab therapy vs treatment withdrawal in patients with moderate to severe plaque psoriasis: a phase 3 randomized clinical trial. JAMA Dermatol. 2020;156(6):1. doi:10.1001/ jamadermatol.2020.0723

44. Gordon KB, Bachelez H, Blauvelt A, et al. Pooled long-term safety analysis of risankizumab in patients with moderate to severe psoriasis. Poster presented at the: 78th Annual Meeting of the American Academy of Dermatology; March 2020; Virtual Conference; 2020.

45. Blauvelt A, Papp KA, Griffiths CEM, et al. Efficacy and safety of guselkumab, an anti-interleukin-23 monoclonal antibody, compared with adalimumab for the continuous treatment of patients with moderate to severe psoriasis: results from the phase III, double-blinded, placebo- and active comparator-controlled VOYAGE 1 trial. $\mathrm{J} \mathrm{Am}$ Acad Dermatol. 2017;76(3):405-417. doi:10.1016/j.jaad.2016.11.041

46. Reich K, Armstrong AW, Langley RG, et al. Guselkumab versus secukinumab for the treatment of moderate-to-severe psoriasis (ECLIPSE): results from a phase 3, randomised controlled trial. Lancet. 2019;394(10201):831-839. doi:10.1016/S0140-6736(19) 31773-8

47. Reich K, Armstrong AW, Foley P, et al. Efficacy and safety of guselkumab, an anti-interleukin-23 monoclonal antibody, compared with adalimumab for the treatment of patients with moderate to severe psoriasis with randomized withdrawal and retreatment: results from the phase III, double-blind, placebo- and active comparator-controlled VOYAGE 2 trial. J Am Acad Dermatol. 2017;76(3):418-431. doi:10.1016/j.jaad.2016.11.042

48. Reich K, Rich P, Maari C, et al. Efficacy and safety of mirikizumab (LY3074828) in the treatment of moderate-to-severe plaque psoriasis: results from a randomized phase II study. Br J Dermatol. 2019;181 (1):88-95. doi:10.1111/bjd.17628

49. Bissonnette R, Maari C, Menter MA, et al. Efficacy and safety of mirikizumab in patients with moderate-to-severe plaque psoriasis: 104-week results from a randomized phase 2 study. Poster presented at the: American Academy of Dermatology (AAD); March 2020; Virtual Conference; 2020. 


\section{Publish your work in this journal}

Biologics: Targets and Therapy is an international, peer-reviewed journal focusing on the patho-physiological rationale for and clinical application of Biologic agents in the management of autoimmune diseases, cancers or other pathologies where a molecular target can be identified. This journal is indexed on PubMed Central, CAS, EMBase
Scopus and the Elsevier Bibliographic databases. The manuscript management system is completely online and includes a very quick and fair peer-review system, which is all easy to use. Visit http://www.dovepress.com/testimonials.php to read real quotes from published authors. 